\title{
Erythema Multiforme Major
}

National Cancer Institute

\section{Source}

National Cancer Institute. Enythema Multiforme Major. NCI Thesaurus. Code C3385.

A severe, sometimes life-threatening, form of erythema multiforme. It is considered to be a hypersensitivity skin reaction triggered by a variety of stimuli, including infections and medication. It is characterized by raised, edematous papules in the extremities;

involvement of one or more mucous membranes; and epidermal detachment involving less than ten percent of the total body surface area. 